\title{
DAS FERRAMENTAS DE BUSCA AO TEXTO: A CONSTRUÇÃO DA IDENTIDADE LGBT EM REVISTAS DIGITAIS
}

\section{FROM SEARCH ENGINES TO THE TEXT: THE LGBT IDENTITY CONSTRUCTION ON DIGITAL MAGAZINES}

MATHEUS NOGUEIRA SCHWARTZMANN*

JEAN CRISTTUS PORTELA*

RESUMO: No presente artigo, buscamos tratar, segundo o ponto de vista da semiótica discursiva, do modo como se dá a seleção e a análise de grandes quantidades de dados que circulam na internet (os big data). Para tanto, discutimos o funcionamento do sistema de indexação das ferramentas de busca na internet, entendido como prática de pré-visualização ou de pré-tratamento que produz uma segmentação dos conjuntos textuais. Partimos do princípio de que um texto, para que tenha seu estatuto semiótico reconhecido, deve adquirir um grau mínimo de presença e que a sua constituição como córpus de pesquisa, em especial no ambiente da internet, deve ultrapassar a pura virtualidade da massa textual, buscando

* Docente da UNESP - Universidade Estadual Paulista. E-mail: matheusns@assis.unesp.br.

** Docente da UNESP - Universidade Estadual Paulista. CNPq. E-mail: jean@fclar.unesp.br. 
a sua atualização que, por sua vez, realizará determinados textos e potencializará outros. Para explicitarmos nossa reflexão, apresentamos uma análise do uso das ferramentas de busca das revistas on-line Veja.com e CartaCapital.com.br. A partir da busca do termo LGBT, termo mais frequente no debate sobre direitos homossexuais e de transgêneros e que melhor se presta à compreensão do modo como a mídia trata a dimensão social da homoafetividade e da diversidade de gênero, buscamos descrever o processo de construção dessa identidade nas duas revistas.

PALAVRAS-CHAVE: Semiótica. Ferramentas de busca. Córpus. Identidade. LGBT.

ABSTRACT: In this paper, we seek to approach, according to the discursive semiotics point of view, how the selection and the analysis of large amount of data on the move on the internet occur (the "big data"). Therefore, we discussed the functioning of the search engine indexing system on the internet, understood as previsualization or pretreatment practice that produces textual group segmentation. We assume that a text, in order to have its semiotic statement recognized, should acquire a minimum degree of "presence", and that its constitution as research corpus, in particular on the internet environment, should surpass the pure virtuality of a textual mass, looking for its "actualization", which in return will "realize" specific texts and will "potentiate" others. To make explicit our thinking, we present an analysis of the search engine use of both Veja.com and Carta Capital online magazines. From the quest of the term "LGBT", term more frequently used in the transgender and homosexual's rights debate and which better fits to understand how the 
media deals with the homoaffectivity social dimension and the gender diversity, we aimed to describe the construction process of this identity on both magazines.

KEYWORDS: Semiotics. Search engines. Corpus. Identity. LGBT.

Talvez não seja impossível elaborar certo número de regras táticas para uma "boa escolha" do corpus: tentamos [...] circunscrever melhor o conceito de representatividade, focalizando dois meios para chegar a isso: a representatividade do corpus pode ser obtida quer por amostragem estatística, quer por saturação do modelo; nesse último caso, o modelo construído a partir de um segmento intuitivamente escolhido e aplicado ulteriormente, para confirmação, complemento

ou rejeição, a outros segmentos, até o esgotamento da informação [...] (GREIMAS; COURTÉS, 2008, p. 105).

\section{Introdução}

0 presente artigo tem por base um duplo desafio: refletir sobre o modo como as ferramentas de busca na internet podem ser assumidas como estratégia de constituição de córpus no vasto horizonte de possibilidades oferecido pela internet, e analisar semioticamente o resultado desse tipo de abordagem.

Buscando dar conta de um modelo de análise possível, escolhemos analisar a maneira como a identidade LGBT é construída nas versões digitais de duas revistas brasileiras de grande circulação, a Revista Veja (Veja.com) e a revista Carta 
Capital (CartaCapital.com.br), cujos sites apresentam ferramentas de busca próprias.

Escolhemos o termo LGBT como objeto de reflexão deste estudo, pois se trata do termo identitário mais frequente no debate social sobre os direitos dos homossexuais e transgêneros e que melhor se presta à compreensão do modo como a mídia trata a dimensão social da homoafetividade e da diversidade de gênero. 0 lexema "LGBT", acrônimo de "Lésbicas, Gays, Bissexuais, Travestis, Transexuais e Transgêneros”, segundo o dicionário Houaiss (2001), de morfologia não concatenativa e que não se revela produtivo em termos de derivação, é utilizado mais frequentemente como adjetivo ("comunidade LGBT") do que como substantivo ("um LGBT") e apresenta variações como LGBTT e LGBTTIS.

Adotamos, pois, para apreender os discursos veiculados nas revistas e o modo como esses discursos compõem a identidade LGBT, o uso do sistema de busca (indexação) dos sites como método de seleção do córpus, o que nos parece uma tática possível para a boa escolha do córpus da qual nos falam A. J. Greimas e J. Courtés (2008, p. 105), mas que, como qualquer escolha, tem suas consequências, como procuraremos demonstrar. Ao lançar, no dia 12 de dezembro de 2015, o termo LGBT no sistema de busca dos sites das revistas, obtivemos como resposta uma série de artigos e reportagens que trazem em seu conteúdo ao menos uma única menção ao termo pesquisado.

Para refletir sobre o modo como se dá a indexação dos textos encontrados, selecionamos os dez primeiros resultados de cada revista, em ordem cronológica. Em nossa hipótese, convém integrar a indexação dos buscadores à reflexão semiótica, na medida em que, para o leitor e para o analista de discursos, ela consiste em uma prática (FONTANILLE, 2008), 
ainda pouco estudada, de pré-visualização ou de pré-tratamento que produz uma segmentação dos conjuntos textuais relevante para sua interpretação posterior.

Dos 20 textos indexados (10 entre 437 em Veja.com e 10 entre 210 na CartaCapital.com.br), analisaremos tão somente 4 (dois de cada revista), que têm em comum o fato de terem sido publicados no dia 08 de junho de 2015, um dia após a realização da 19a Parada do Orgulho LGBT da cidade de São Paulo. Chamaremos esse critério de segmentação dos resultados de busca de parâmetro de controle da indexação, no caso da nossa escolha, um parâmetro temporal, que poderia ser também actorial ou espacial ou, ainda, narrativo.

Com isso, nosso objetivo será evidenciar que, por mais que os buscadores sejam ferramentas relevantes no trabalho do analista de discursos, que podem gerar resultados de análise bastante representativos, sua pertinência se restringe essencialmente ao nível do texto-ocorrência, o que obriga o analista a formular suas próprias hipóteses de caráter discursivo, que darão coerência e pertinência ao córpus, a depender do problema tratado.

Nossa reflexão sobre as ferramentas de busca procurará também problematizar as relações entre indexação textualizada (o conjunto de resultados de uma busca no Google, por exemplo) e textos indexados (os resultados particulares da busca), buscando compreender, nos casos das ferramentas de busca das revistas Veja.com e CartaCapital.com.br, que sentidos são construídos pela análise da indexação e que outros se acrescentam quando o leitor-usuário ou o analista de textos debruça-se detidamente sobre os textos arrolados pela ferramenta de busca. 


\section{A constituição de um córpus por meio de buscadores}

Para que se possa constituir um córpus de análise, de modo geral, é preciso que se adotem estratégias textuais e/ou discursivas que permitam constituir um repertório de ocorrências, de casos particulares, que satisfaçam a um princípio geral de análise. Na falta de recursos informáticos, dependemos essencialmente da intuição e da erudição, da nossa capacidade de investigação em bibliotecas e arquivos, e sofremos coerções geográficas, financeiras e, especialmente, cognitivas. Estas últimas colocam limites práticos ao volume de texto e de discurso que podemos ler por mês, por dia e por hora.

Do ponto de vista cognitivo, ler para constituir um córpus significa indexar, isto é, colocar em evidência determinadas ocorrências (os dados) e organizá-las segundo certos princípios (os quais podemos chamar de metadados), estabelecendo classes e subclasses (segundo determinadas hierarquias). A leitura como processo de indexação, consciente ou inconsciente, ou ainda, explícita ou implícita, parece-nos uma condição da leitura entendida como compreensão.

Nesse sentido, como podemos compreender, ler, acessar e organizar, enfim, os dados (ou, mais precisamente, nesse caso, os metadados, também conhecidos como big data) que estão abrigados na internet, e que são um volume flutuante, dinâmico e dificilmente quantificável de textos? 0 problema que se formula com essa questão é o da visibilidade ou da presentificação dos textos. Para que tenha seu estatuto semiótico plenamente reconhecido, um texto precisa adquirir um grau mínimo de presença. Se colocássemos essa questão em termos de existência semiótica, obteríamos o seguinte: como ultrapassar a pura virtualidade da massa textual e ter acesso a 
uma atualização, ainda que provisória, que, por sua vez, realizará determinados textos e potencializará outros tantos.

No que diz respeito ao córpus deste trabalho, podemos certamente imaginar que existam textos que tratam da questão LGBT. Mas onde estão eles? Quantos são? De que tipo e extensão? Conseguiríamos, ou melhor, "perviríamos", na esteira das reflexões de Zilberberg (2007), encontrá-los, caso adotássemos a boa via de acesso (a da "implicação", portanto)? Quantos deles surgiriam (ou sobreviriam) de modo improvável, inusitado, na forma de um achado (da ordem da "concessão")?

É em meio a esse cenário intricado, pleno de possibilidades, que os mecanismos de busca surgem como uma contribuição para a constituição de um córpus. Isso porque, como sabemos, os mecanismos de busca são capazes de indexar um grande volume de textos: de dezenas, centenas, a milhares ou milhões de ocorrências. Essa indexação é baseada em um algoritmo que, por meio de metadados, consegue tornar visível e organizar a massa textual. Essa visibilidade é afetada por fatores financeiros (inserções pagas), linguísticos, geográficos, temporais e identitários (cookies e históricos de navegação). A indexação compreende, desse modo, parâmetros enunciativos (ator, espaço e tempo) e pode ser concebida, consequentemente, em sua forma embreada (uma busca que se faça segundo hábitos de pesquisa de um certo usuário em um espaço e um tempo da concomitância do ato de busca) ou debreada (a busca impessoal - usuário sem IP e/ou sem histórico de navegação -, em um espaço e tempo outros, não concomitantes). Embora essa perspectiva de análise também nos pareça produtiva e promissora, no caso do nosso trabalho, não tratamos a breagem da indexação como categoria pertinente de análise.

A indexação, portanto, não é uma operação transparente, utilitária, no grau zero da busca, mas uma operação 
complexa da qual o usuário conhece, em geral, tão somente o resultado final, que chamaremos de indexação textualizada. A indexação textualizada é aquela que aparece para o usuário como produto da busca, na tela de seu navegador, em um computador, smartphone ou tablet, sob a forma de um texto compreensível para o usuário ou leitor comum, podendo se apresentar como um texto de predominância verbal (Google Web), não verbal (Google Imagens) ou sincrética (Google Notícias). Falamos em termos de predominância, pois acreditamos, por fim, que as páginas de internet, assim como as páginas do meio impresso, devem ser lidas sempre como semióticas sincréticas, na medida em se constituem a partir de instruções visuais de diagramação (inferior/superior, anterior/posterior, central/marginal, intercalante/intercalado, etc.) e formatação (tamanho, densidade, contraste, etc.), que atenuam ou intensificam as propriedades do texto verbal.

\subsection{Os metadados enunciados na indexação textualizada}

Os metadados são metainformações, isto é, são dados que servem para identificar (indexar) outros dados. Essa identificação, tradicionalmente, envolve coordenadas espaço-temporais que especificam uma identidade. São velhos conhecidos dos bibliotecários e dos programadores - e, atualmente, dos editores de periódicos científicos - e desempenham um papel fundamental na textualização da indexação.

O Google (Figura 1), por exemplo, apresenta como metadados enunciados como título; link; fragmento do texto; e data da última visita. Como metadados não enunciados, po- 
demos citar a pertinência atribuída pelo próprio buscador Google para apresentar em primeiro lugar uma entrada e não outra, o que vai acontecer devido à comercialização da posição no índice (indicação de compra de um produto) ou à sua atualidade (notícia de um atentado que acaba de acontecer) ou recorrência (hábitos dos usuários).

Figura 1 - Metadados enunciados de Google.

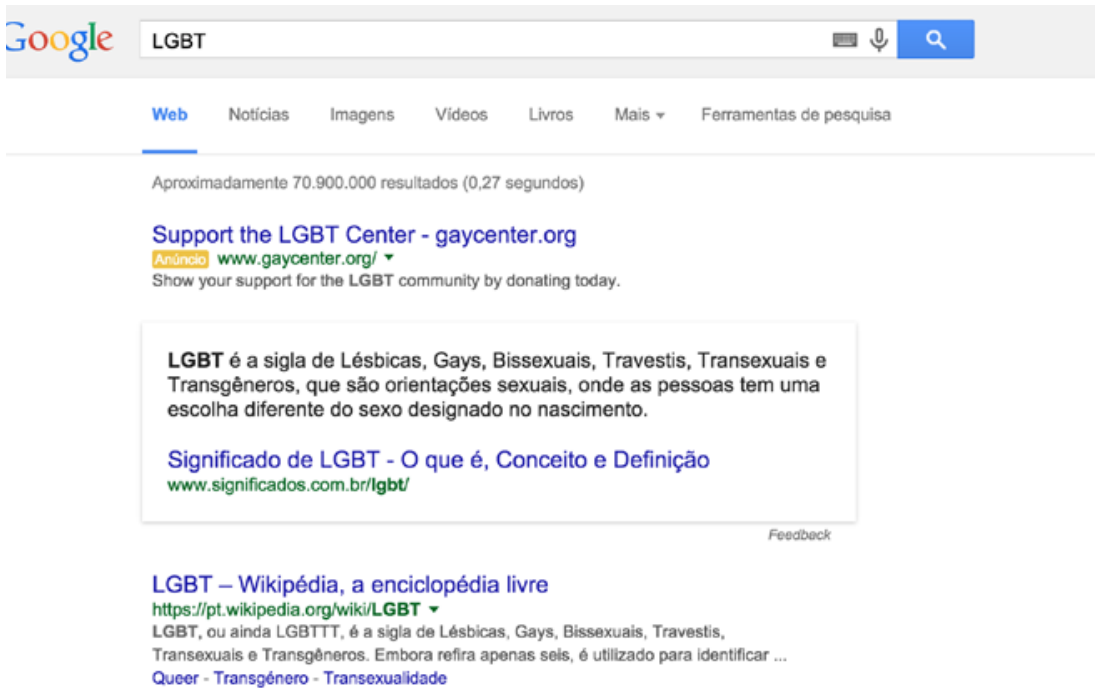

Fonte: Resultado de busca para o termo LGBT em google.com.

Nas versões on-line das revistas que são objeto deste trabalho, os metadados alinham-se a formas enunciativas próprias à sua constituição genérica (PORTELA; SCHWARTZMANN, 2012), em especial aquela de suas versões impressas. Desse modo, diferentemente dos metadados de uma ferramenta de pesquisa como o Google, as ferramentas das revistas trazem à tona elementos de indexação que só fazem sentido no interior das publicações on-line. 
Em Veja.com (Figura 2), por exemplo, temos como metadados: a editoria; o título-link; a seção/gênero; a publicação; o fragmento do texto e a data de criação/veiculação do texto. Desse modo, o termo LGBT buscado retorna como resultado da busca já inserido em determinadas categorias, como por exemplo, "Entretenimento", "Mundo" e "Brasil", que são evidentemente seções da revista. Essas categorias, no entanto, já apontam para um procedimento de triagem operado pela revista e evidenciado pela ferramenta de busca: nessa indexação enunciada, temos acesso a procedimentos de atualização e realização, os quais sugerimos anteriormente, segundo apenas as potencialidades previstas no interior do discurso da revista Veja.com.

Figura 2 - Metadados enunciados de Veja.com.

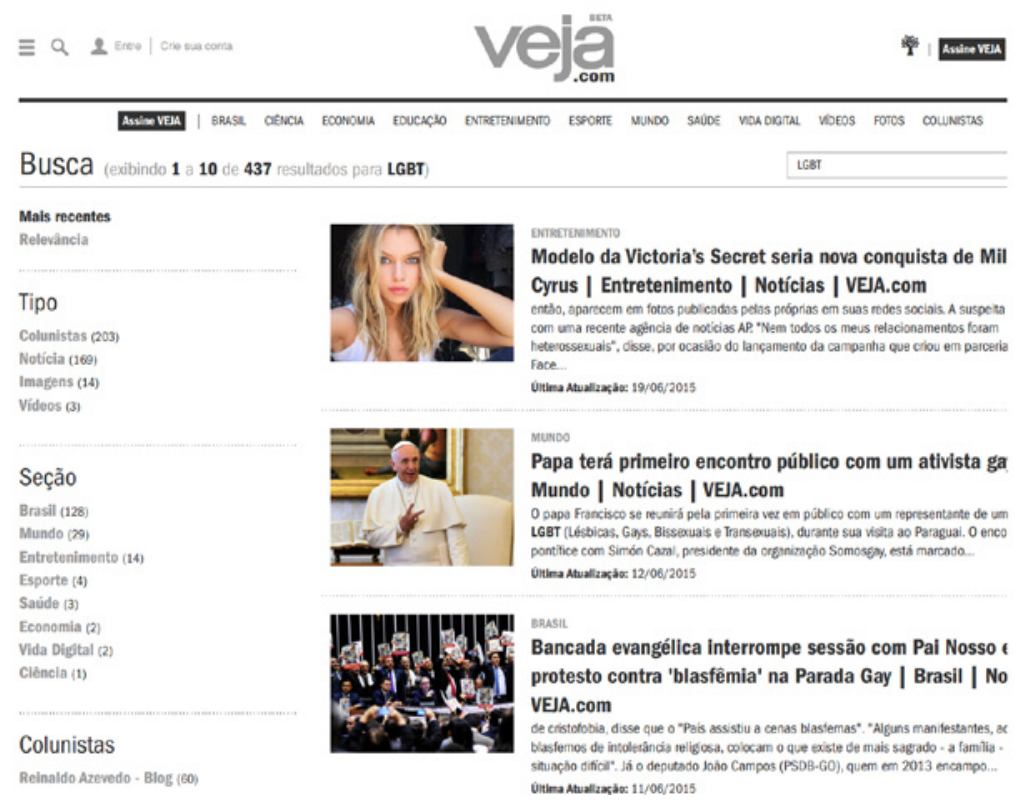

Fonte: Resultado de busca para o termo LGBT em Veja.com 
Em CartaCapital.com.br (Figura 3), os metadados se organizam de modo semelhante, e têm-se assim o título-link; o fragmento do texto; a localização/seção; as tags (palavras-chave que servem à indexação). Nesse caso, as categorias também estão ligadas às seções da revista, como por exemplo, "Território de Maíra" e "Outras palavras" (blogs relacionados à CartaCapital.com.br), e "Sociedade". Há aqui o mesmo procedimento de atualização e realização de potencialidades que estão já previstas no interior do discurso da revista.

Figura 3 - Metadados enunciados de CartaCapital.com.br

CartaCapital assive

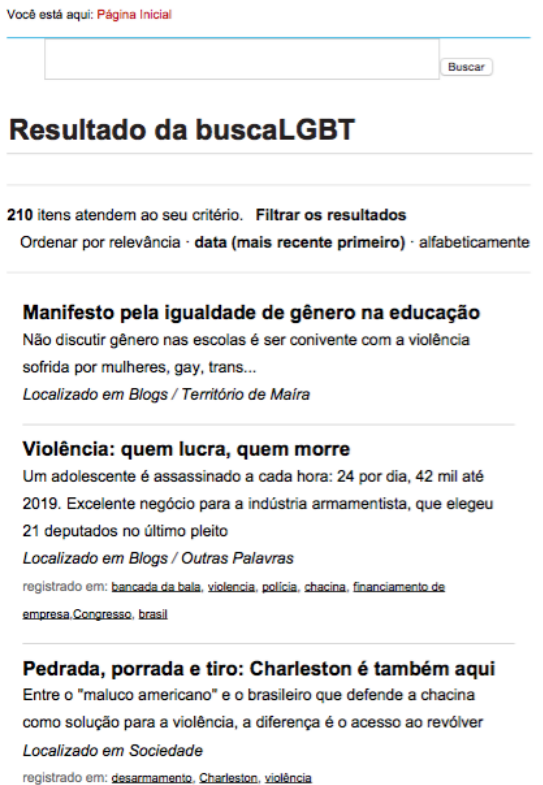

Fonte: Resultado de busca para o termo LGBT em www.CartaCapital.com.br 
De um modo geral, o usuário comum não tem consciência da importância da apresentação e da manipulação de metadados nas buscas que faz pela internet. Eis porque o ato de ler na internet, além de ser atividade compreensiva própria à leitura, nos permite formular questões relativas à indexação e ao tratamento dos dados.

Tanto em um caso como no outro, a indexação pode se dar de modo alfabético, cronológico ou por relevância, a relevância estando ligada, em geral, à quantidade de ocorrências do termo buscado (se o termo aparece no título, na linha fina, etc.) ou, ainda, pela quantidade de acessos que um dado link recebeu.

Realizada a indexação inicial, em Veja.com e CartaCapital.com.br, seguindo uma tendência antecipada pelo Google e, antes dele, por AltaVista e Yahoo (os primeiros buscadores de conteúdo on-line), é possível refiná-la, isto é, reindexá-la por Tipo (de texto), Seção, Colunistas e Data (hoje, última semana, último mês ou um intervalo preciso de datas). Isso só é possível graças às marcações (tags) por metadados.

\section{Ler a indexação}

Se a indexação é textualizada, ela deve ser lida como um texto, cujo propósito é introduzir o leitor-usuário ao universo do tema pesquisado. Ao lado das bulas de remédio e dos manuais de instrução, haveria um lugar para a textualidade fragmentária gerada pela indexação, cuja natureza injuntiva é evidente. A injunção no caso da indexação não é propriamente uma injunção relacionada a uma explicação passo a passo, como ocorre frequentemente em textos chamados injuntivos ou instrucionais, mas a injunção presumida de uma apreen- 
são discursiva difusa, alusiva, que nos sugere certas figuras e certos temas e que, segundo a competência do leitor, produz um discurso de maior ou menor coerência isotópica. 0 que falta no enunciado, que é lacunar, gerado de modo automático, recupera-se na enunciação.

É assim que nos damos conta de que, em Veja.com, ao pesquisar o termo LGBT usando como critério a cronologia inversa, entre 10 resultados analisados (Cf. Anexo 1), obtivemos 4 textos da editoria de entretenimento e 3 textos de colunistas anti-LGBT. 0 que resta dessa sugestiva proporção é dedicado ao pitoresco: o Papa se encontra com um ativista gay, a bancada evangélica condena a blasfêmia na Parada Gay e evangélicos lutam contra a homofobia. A indexação revela recorrências significativas que, se no âmbito do algoritmo de busca, se resumem à aparente neutralidade dos metadados, no âmbito do discurso, ao contrário, indicam um modo engajado de abordar a identidade LGBT, que explora seus aspectos interditos ou polêmicos e que dá voz àqueles que contestam sua relevância social.

Na CartaCapital.com.br, a indexação textualiza diferentemente o universo LGTB, que passa a ser o âmbito de debates que envolvem a educação, a violência, a legalidade, a ética e os direitos humanos. Curiosamente, apenas 3 textos (Cf. Anexo 2) exploram frontalmente a questão LGBT, enquanto os demais fazem menções pontuais, não muito distantes do fait divers, mas em uma leitura pró-LGBT: violência contra jovens em geral, a invasão do computador do deputado Marco Feliciano por hackers coloridos; e o impacto da lei do silêncio de Brasília na atividade de bares e boates. 


\section{A identidade LGBT em Veja.com e CartaCapital. com.br}

Ao comparar os textos que encontramos a partir de nossa busca nas duas revistas on-line, chegamos a discursos bastante marcados por formas de "elogio" e de "depreciação" (Cf. SCHWARZTAMNN, 2013) de certas identidades (ainda que gerais): a identidade LGBT, que recobre um vasto número de papeis temáticos particulares, e que foi nossa escolha desde o início, e a identidade evangélica e/ou religiosa, que, do mesmo modo, recobre uma série de papeis temáticos bastante singulares, e que surgiu, como mostraremos, como contraponto à identidade LGBT.

Nos quatro textos estudados (dois de cada revista), o enunciador assume uma posição de destinador-julgador, tomando o Outro (de quem se fala) como objeto de depreciação: nesse caso, os valores do outro são enfraquecidos, e se busca a deterioração e o apagamento dos valores.

Em todos os casos, embora sob estratégias distintas, podemos ver o enfraquecimento ou mesmo a deterioração dos valores das identidades, seja a LGBT, seja a religiosa. Vejamos como isso se dá, mais detalhadamente, em cada uma das revistas.

\subsection{Veja.com}

A primeira publicação que tomamos para análise é de autoria de Felipe Moura Brasil e se intitula "Parada LGBT: Dinheiro público para atacar cristãos. Lésbica critica movimento: são uns 'vitimistas do c@r@***'!” (Figura 4). 0 texto, altamente figurativo, vai atribuir à identidade LGBT, já no 
primeiro parágrafo, uma dimensão política e, mais especificamente, partidária: segundo o enunciador, a comunidade LGBT é petista, financiada pela prefeitura de São Paulo e pelo Governo Federal (nas instituições da Caixa Federal e da Petrobrás). Essa associação terá consequências.

Figura 4 - Publicação de Felipe Moura Brasil em Veja.com

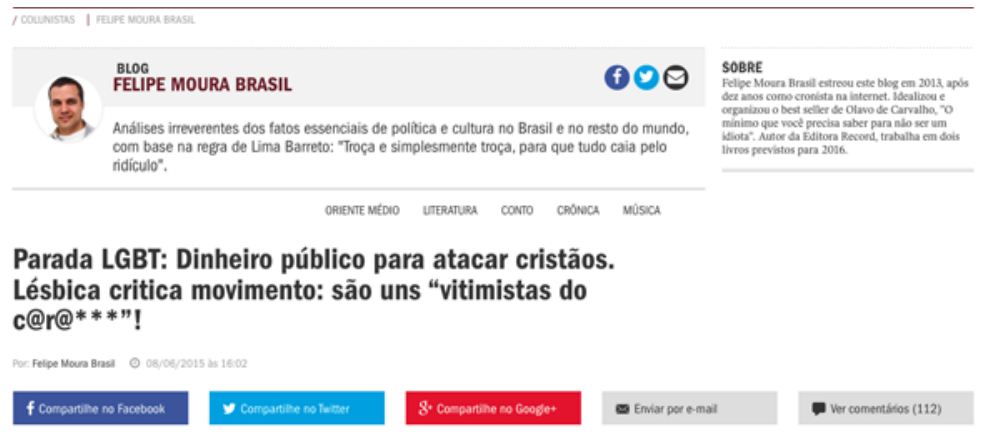

Fonte: Revista Veja.com

Ainda no primeiro parágrafo, temos as figuras "um transexual seminu" e "Jesus Cristo", que nos levam a dois procedimentos de invalidação da identidade LGBT. Primeiramente, o uso do artigo indefinido e do adjetivo, ambos no masculino, desrespeita a identidade da mulher trans. Tratá-la no masculino é lhe (re)conduzir, à força, à identidade que já desconstruiu. É não aceitar, portanto, o seu devir.

A segunda invalidação operada pelo enunciador diz respeito à religiosidade: uma vez petista (figura que pode ser lida como análoga à figura comunista, nesse caso), a mulher trans (e a comunidade LGBT, por extensão metonímica) tem sua fé na cristandade e seu gesto de protesto invalidados: o petismo/comunismo, ateu por natureza, como o diz o discurso do senso comum, chega a ser, aqui, anticristão. Isso se 
comprova no título da matéria (dinheiro público para atacar cristãos) e no segundo parágrafo, em que se acusa a esquerda de achar natural ironizar Jesus Cristo, embora critique a ironia à fé islâmica.

Ao tratar da fé islâmica, o texto busca evidenciar, por uma espécie de entimema, a incoerência na relação instaurada pelo próprio texto, entre Governo do PT e comunidade LGBT: se o PT apoia o Islã (na figura do Irã), e o Islã mata homossexuais, logo o PT mata homossexuais. 0 argumento é frágil. E então a ele se soma um segundo modo de depreciação da identidade LGBT, talvez o modo o mais eficaz: a autodepreciação.

A figura da lésbica (Karol Eller) liberta das amarras de um suposto movimento político LGBT surge no texto graças a um procedimento de delegação de voz, que permite a implosão de sua própria identidade: depois de um desabafo colérico ("movimento de merda", "vitimistas do caralho"), vem a pérola do senso comum: "para ter respeito, a gente tem que dar respeito". A fórmula é curiosa: para ser respeitado enquanto identidade autônoma (enfim, para ser) o sujeito deve não ser: paradoxo intransponível que anula a existência de uma identidade.

Do ponto de vista da figuratividade, ainda, podemos até mesmo descrever o corpo dessa identidade LGBT que é construída nesse primeiro texto. 0 uso do calão para se referir à própria comunidade LGBT, e, especialmente, o uso concomitante de figuras relacionadas ao sexo e a necessidades fisiológicas, à escatologia, tornam esse corpo, já de início desnudado, vil, grosseiro e, de certo modo, eroticamente grotesco.

No segundo texto de Veja.com, teremos procedimentos de depreciação muito parecidos com os já descritos. Intitulada "Nua e suja de tinta, Miley Cyrus abraça porco em revista" 
(Figura 5), a matéria descontrói a isotopia que deveria ser a principal: a cantora norte-americana posou para a revista $\mathrm{Pa}$ per (Figura 6) por conta de seu trabalho de caridade junto a sua fundação que ajuda crianças e adolescentes da comunidade LGBT (informação que consta do $2^{\circ}$ parágrafo). No entanto, toda a construção figurativa da reportagem vai erotizar, e mesmo animalizar, a jovem cantora que, por apoiar abertamente o movimento LGBT, é tomada, ela mesma, como pertencente a essa identidade.

Figura 5 - Publicação da Redação de Veja.com

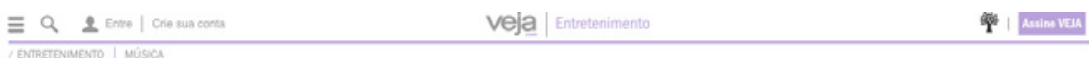

Nua e suja de tinta, Miley Cyrus abraça porco em revista

Cantora aparece na 'Paper', a publicaçāo que no ano passado trouxe em sua capa a socialite Kim Kardashian equilibrando uma taça de champanhe no derrière

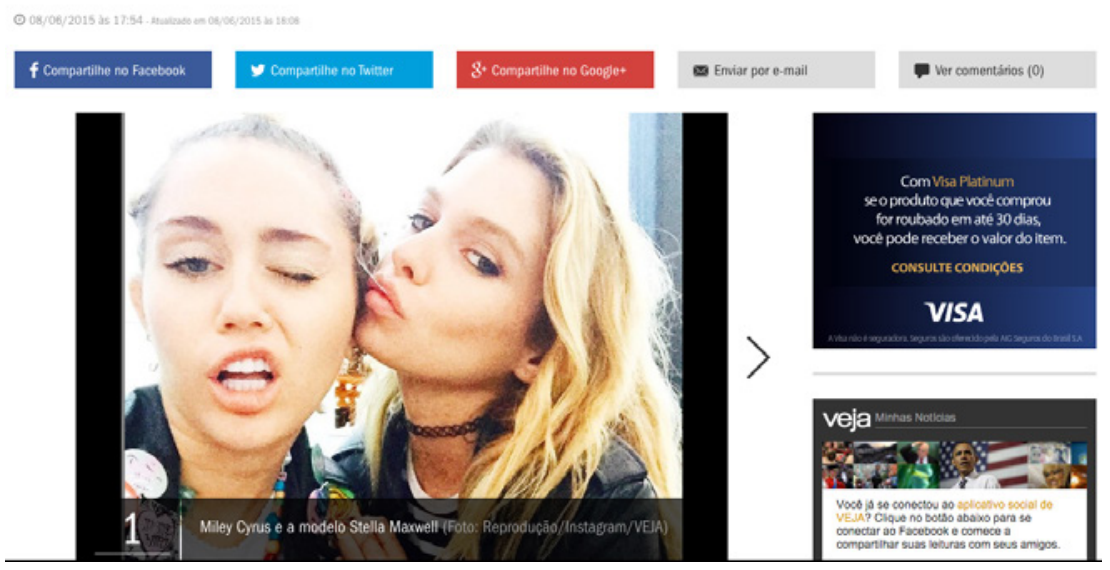

Fonte: Revista Veja.com. 
Figura 6 - Capa da revista Paper

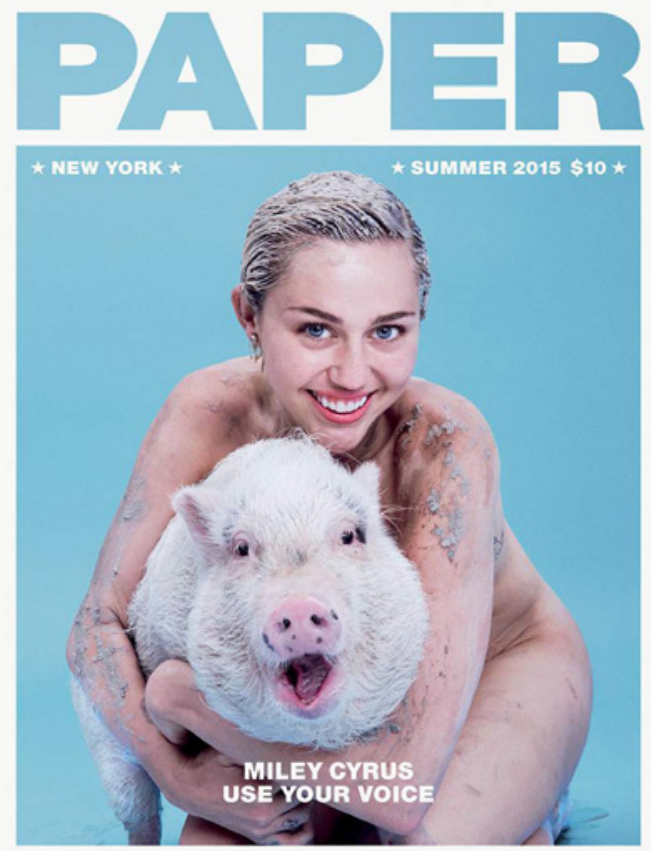

Fonte: Revista Paper.

Já no título, as figuras "nua", "suja” e "porco" propõem um percurso figurativo da sujidade, da porcaria, literalmente. Há aí uma tensão erótica próxima àquela produzida no texto anterior: o corpo nu e seu sexo são, ambos, sujos.

Na linha fina, duas figuras que reforçam a isotopia da erotização: "Kim Kardashian" (socialite norte-americana que se tornou celebridade por protagonizar um filme erótico caseiro) e derrière (termo francês, utilizado de modo eufêmico para se dizer "traseiro", pouco usual atualmente). No primeiro parágrafo: "pouca roupa"; "nua”; "suja”. E a depreciação mais uma vez literalmente enunciada: "como se isso não bastasse, abraçada a 
um porco". Miley Cyrus ultrapassa, assim, os limites do tolerável, segundo os valores construídos pelo enunciador.

No penúltimo parágrafo, a identidade da cantora desaparece: temos "Kim Kardashian", de novo, um comentário sobre a revista Paper, que propôs o ensaio, e até mesmo a figura "Valesca Popozuda", famosa cantora de funk brasileira: há desse modo um apagamento total da identidade de Miley. Vale dizer que na capa da revista Paper pode-se ler: "Miley Cyrus use your voice". Voz que foi totalmente apagada na matéria de Veja.com.

No último parágrafo, mais um gesto de depreciação e rejeição da identidade de M. Cyrus, na medida em que seu corpo de mulher sexualizado/erotizado é rejeitado (pois é da ordem do não dever ser), e somente seu corpo infantil, assexuado, hoje inexistente, é aceito (pode ser): “Miley é só fofura [...] quando tinha 12 anos". Há nesse caso o mesmo tipo de interdição operada contra a identidade LGBT, que só pode existir se for parcial, se tiver sua sexualidade negada. Do contrário, nenhum direito à existência.

É curioso notar que, justamente um dia depois da Parada LGBT na cidade de São Paulo, os únicos textos que trazem o lexema LGBT organizam-se como discursos depreciativos (até mesmo intolerantes) que rejeitam a própria identidade (ou as identidades) e o universo de valores LGBT. Poderíamos dizer, desse modo, que o discurso construído pelo enunciador Veja.com é um discurso impermeável e reacionário, que reage fortemente a valores que não são os seus.

\subsection{CartaCapital.com.br}

Os dois textos publicados on-line por CartaCapital.com. br têm características comuns entre si: são mais temáticos 
que figurativos, ou seja, ao invés de nos apresentar o simulacro de uma dada realidade, buscam explicar essa realidade, e vão construir a identidade LGBT em oposição a valores imputados aos políticos religiosos.

0 primeiro texto, intitulado "Vão ter que engolir os LGBT", de Maurício Moraes (Figura 7), é uma espécie de manifesto à resistência da identidade LGBT: apresenta o contexto que antecedeu a Parada do dia 07 de junho e narra uma vitória do movimento.

\section{CartaCapital \\ ESSINE Politica Economia Sociedade Cultura Internacional Blogs e colunistas Mais conteúdo}

\section{Vocé está aqui: Página Inicial / Sociedade / Vão ter de engolir os LGBT}

\section{Sociedade}

Opiniăo

\section{Vão ter de engolir os LGBT}

por Nauricio Noraes - publicado 0808:2015 12h25

A cruzada moralista contra minorias esconde a pilantragem dos que tratam a religião como negócio

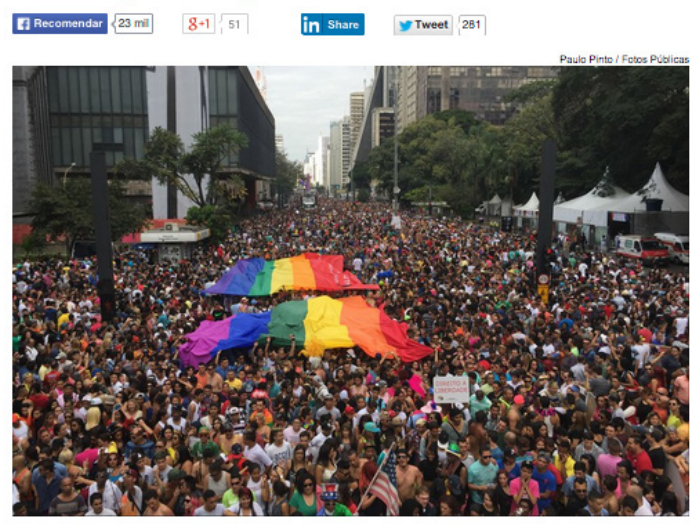

A Parada Gay em São Paulo, no domingo 7

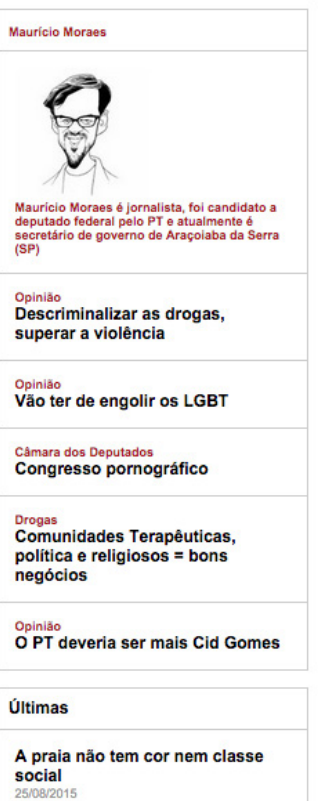

Fonte: Revista CartaCapital.com.br.

Na semana da Parada do Orgulho LGBT, o pastor Silas 
Malafaia convocou um boicote a uma marca de perfumes, cuja campanha trazia dois casais homoafetivos. A resposta do mercado tendo sido favorável à marca, o enunciador do texto narra a vitória de uma batalha em meio à guerra que o movimento LGBT trava com o que ele chama de "Cruzada dos costumes". E a isotopia bélica se confirma no texto: "Cruzada"; "exército de fiscais da vida alheia"; "tiro saiu pela culatra"; "batalha".

No entanto, dentre os 16 parágrafos do texto, apenas 5 afirmam a identidade LGBT, o fazendo sempre de modo parcial e estereotipado:

$\S 3^{\circ}$ : "a marca ganhou ares cult";

$\S 6^{\circ}$ : "direitos LGBT conquistados";

$\S 7^{\circ}$ : "LGBTs saindo do armário, vivendo vida normal, sem privilégios, com igualdade de direitos";

$\S 9^{\circ}$ : "assumimos postos de comando [...] nós existimos".

Eis os temas que constroem a identidade LGBT no texto: sofisticação; modernidade; igualdade. Ou seja, a visibilidade LGBT é tão ampla e avança sobre tantos valores que mal chega a se delinear como identidade, no que concerniria a um processo de individuação.

Nesse sentido, se por um lado há uma atenuação no processo de construção da identidade LGBT, por outro, há uma amplificação do ataque aos políticos religiosos, que é construído sob uma isotopia figurativa do mau-caratismo: "interesses escusos"; "mundo evangélico pilantra"; "hostilidade desmesurada dos fundamentalistas"; "religião negócio"; "ganância desmedida"; "vender a palavra de Deus"; "Malafaia é perigoso", entre outras figuras. Trata-se, portanto, mais de um procedimento de depreciação de uma anti-identidade LGBT que do elogio da identidade LGBT em si mesma.

O segundo texto, intitulado "A crucificação da artista 
transexual", de Jean Wyllys (Figura 8), organiza-se de maneira semelhante ao primeiro. Embora o texto de Wyllys traga no título "a artista transexual", esse assunto não se desenvolve plenamente, uma vez que, embora a artista seja tratada segundo a sua própria identidade (usa-se a definição "mulher trans" e os pronomes de tratamento empregados estão no feminino; há a valorização da profissão "artista", por exemplo), a questão da identidade trans é abandonada ao longo do texto, que muda de foco e passa a um discurso em favor da defesa de um estado laico.

Figura 8 - Publicação de Jean Wyllys em CartaCapital.com.br

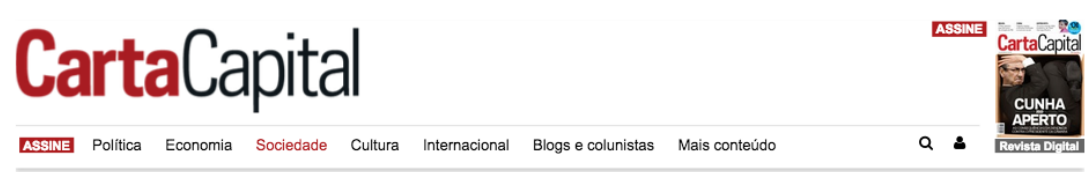

Você está aqui: Página Inicial / Sociedade / A crucificaçăo da artista transexual

\section{Sociedade}

Direitos LGBT

\section{A crucificação da artista transexual}

por Jean Wyllys - publicado 08/06/2015 19h17

Notas sobre a epidemia de estupidez, a "indignação" seletiva e as estratégias de difamação

f Recomendar $\langle 40 \mathrm{mil} \quad 8+1 \sqrt{101}$

A iconografia cristã católica (ou seja, as representações dos "santos" e "mártires" reconhecidos pela Igreja Católica ao longo de sua existência) e as narrativas que the deram origem e lhes sustentam (a Bíblia e a hagiografia) vêm servindo de inspiração $e$ material para as artes laicas desde a Independência Americana (1776) e a Revolução Francesa (1789) - eventos marcantes da emergência do que in Share 11 Tweot 705

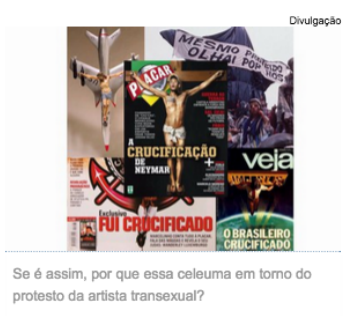

Últimas

A praia não tem cor nem classe social

(50)

Brasil finaliza compra de 36 caças suecos

Reforma ministerial deve ter pouco impacto econômico 25/08/2015

Presos não podem ser fonte de lucro

Um campeonato indigena decidido no par ou impar

25/08/2015

Mais lidas

Na Semana no Més

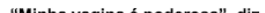

Fonte: Revista CartaCapital.com.br 
Ainda mais temático que o primeiro, a erudição será a sua tônica: aproximando-se do discurso científico, o enunciador defende a cultura, a educação e mesmo a norma culta como valores que permitem a manutenção e a defesa de uma identidade LGBT.

0 curioso é que, ao fazer a defesa de uma identidade LGBT, plural e baseada na democracia e na liberdade, o enunciador adota um discurso elitista e impositivo (as diversas exclamações ao longo do texto o confirmam), como atestam os seguintes períodos: "estupidez contagiosa"; "as pessoas só poderiam mesmo embarcar nessa celeuma homofóbica, escrevendo em português fora da norma"; "evangélico fanático", por exemplo.

Além disso, a crítica que faz aos gays de classe média e média-alta recai sobre uma série de valores estereotipados, construídos de modo exemplar na seguinte passagem:

Até mesmo muitos gays de classe média e média-alta foram incapazes de extrair sentido tão óbvio da performance artística transexual, o que mostra que as viagens ao exterior, a música eletrônica, as drogas sintéticas consumidas nas baladas, as calças da Diesel e as cuecas da Calvin Klein não os tornam imunes à epidemia de estupidez nem à homofobia internalizada, ao contrário! (WYLLYS, 2015, grifo nosso).

Os percursos figurativos construídos no texto elencam os hábitos (poderíamos até mesmo pensar nas formas de vida) e o tipo de cultura que esses gays consumiriam (viagens, música eletrônica, drogas, marcas de roupa como Diesel e Calvin Klein), avaliados todos como comportamentos reprováveis. Os temas da futilidade, da promiscuidade, da vaidade e da luxúria, tão frequentemente negados pelo movimento 
LGBT, e tão frequentemente imputados à identidade LGBT por aqueles que a ela reagem, ganham força na boca de Jean Wyllys, ele mesmo gay. Essa força nos lembra, naturalmente, o procedimento de delegação de voz que ocorre em Veja.com, procedimento que permite, como dissemos, a implosão da identidade LGBT: a avaliação depreciativa parte, nesse caso como no outro, do juízo de um membro da comunidade, que, por essa razão, seria mais competente para sancionar negativamente a (sua própria) identidade LGBT.

\section{Algumas considerações}

A orientação que a indexação propõe no momento em que se faz uso de uma ferramenta de busca da internet se mantém ou se transforma na leitura dos artigos indexados. De fato, ou a elasticidade do discurso vai garantir a expansão daquilo que estava sugerido e condensado (a realização), mas já organizado isotopicamente na indexação das revistas digitais, ou as palavras-ocorrências vão ser sobremodalizadas no interior do discurso para atenuar ou amplificar (a potencialização) um dado sentido no enunciado.

No caso de Veja.com, a posição anti-LGBT se confirma: desumanização, demonização e animalização são os procedimentos discursivos empregados na desconstrução de uma identidade LGBT, que se revela interdita e sem voz (especialmente se nos lembramos do comentário sobre a capa da revista com Miley Cyrus).

Na CartaCapital.com.br, embora o universo LGTB seja da ordem do possível e do aceitável, os debates tocam a questão sempre marginalmente: a suposta abertura do universo de valores conhece um fechamento (uma triagem) por par- 
te de Jean Wyllys, por exemplo, que, para defender a causa LGBT, faz duras críticas a classes sociais e usos da língua. No caso específico dos textos indexados em nossa busca, a identidade LGBT serve de contraposição e mesmo de arma contra um discurso religioso dito fundamentalista. Nesse contexto, o termo LGBT é a senha para o debate político, e não para o debate sobre o humano. CartaCapital.com.br explora sobretudo a dimensão do valor do valor, do peso que o argumento LGBT pode adquirir no debate político. Não se tem, de todo modo, um procedimento de complexificação dessa identidade, naquilo que é sua marca: a diversidade de formas de vida que nela podem (co) existir.

A análise comparada da indexação textualizada e dos textos indexados nos mostra a importância da leitura vertical das textualidades que povoam a internet. Não raramente, na sua relação com as ferramentas de buscas, o leitor-usuário se contenta com a indexação textualizada, sem o cuidado de ler em detalhes os textos indexados para obter uma primeira apreensão geral do tema pesquisado. Argumentos de autoridade comuns como "Está na internet!" e "Não encontrei no Google!" nos mostram como as práticas de busca e de indexação na internet incidem sobre a nossa forma de nos informar, de ler e de analisar o estatuto dos textos que lemos.

Podemos pensar que o conhecido argumento de que algo é "verdade" porque foi lido em um livro ou visto na TV ou ouvido no Rádio não é tão diferente. No entanto, nem os livros, nem a TV e nem o Rádio apresentam o número quase incontável e muito heterogêneo de textos, fontes, gêneros e registros enunciativos que a internet nos proporciona como plataforma armazenadora e indexadora. 0 fato é que nos âmbitos editorial, televisivo e radiofônico, distinguimos mais precisamente as operações de construção, edição e autoria. 
Na cultura digital, indexar, mais do que nunca, confunde-se com ler, o que equivale a dizer que poder confunde-se, inadvertidamente, com saber. A semiótica, pela análise global que pode fazer da indexação textualizada e dos textos indexados, coloca em xeque essa concepção de conhecimento: o que está ao alcance do mouse não é o mundo, é o seu sumário.

\section{REFERÊNCIAS}

BRASIL, F. M. Parada LGBT: Dinheiro público para atacar cristãos. Lésbica critica movimento: são uns 'vitimistas do c@r@***'! Revista Veja.com. 8 jun. 2015. Disponível em: <http://veja.abril.com.br/blog/felipe-moura-brasil/cultura/ parada-lgbt-dinheiro-publico-para-atacar-cristaos-lesbicacritica-movimento-sao-uns-vitimistas-do-cr/>. Acesso em: 12 dez. 2015.

DICIONÁRIO ELETRÔNICO HOUAISS. Versão 1.0. Editora Objetiva, 2001.

FONTANILLE, J. Pratiques sémiotiques. Paris: PUF, 2008.

GREIMAS, A. J.; COURTÉS, J. Dicionário de Semiótica. Trad. Alceu Dias Lima et. al. São Paulo: Contexto, 2008.

MORAES, M. Vão ter que engolir os LGBT. CartaCapital. 8 jun. 2015. Disponível em: <http://www.cartacapital.com.br/ sociedade/vao-ter-de-engolir-os-lgbt-1841.html>. Acesso em: 12 dez. 2015.

NUA E SUJA DE TINTA, MILEY CYRUS ABRAÇA PORCO EM 
REVISTA. Revista Veja.com. 8 jun. 2015. Disponível em: $<$ http://veja.abril.com.br/noticia/en tretenimento/nua-esuja-de-lama-miley-cyrus-abraca-porco-em-revista>. Acesso em: 12 dez. 2015.

PORTELA, J. C. Semiótica midiática e níveis de pertinência. In: DINIZ, M. L. V. P.; PORTELA, J. C. (Org.). Semiótica e Mídia: textos, práticas, estratégias. Bauru-SP: Unesp/Faac, 2008b. p. 93-113.

SCHWARTZMANN, M. N. Elogio e depreciação no comentário on-line. In: ABRIATA, Vera Lucia et al. Leitura: a circulação dos discursos na contemporaneidade. Franca-SP: EDUNIFRAN, 2013. p. 55-85.

WYLLYS, J. A crucificação da artista transexual. CartaCapital. 8 jun. 2015. Disponível em: <http://www.cartacapital.com. br/sociedade/a-crucificacao-da-artista-transexual-9268. html>. Acesso em: 12 dez. 2015.

ZILBERBERG, C. Louvando o acontecimento. Trad. Maria Lucia Vissotto Paiva Diniz. Revista Galáxia, São Paulo, n. 13, p. 1328, jun. 2007. 
Matheus Nogueira SCHWARTZMANN, Jean Cristtus PORTELA

\section{Anexo 1 - Veja.com}

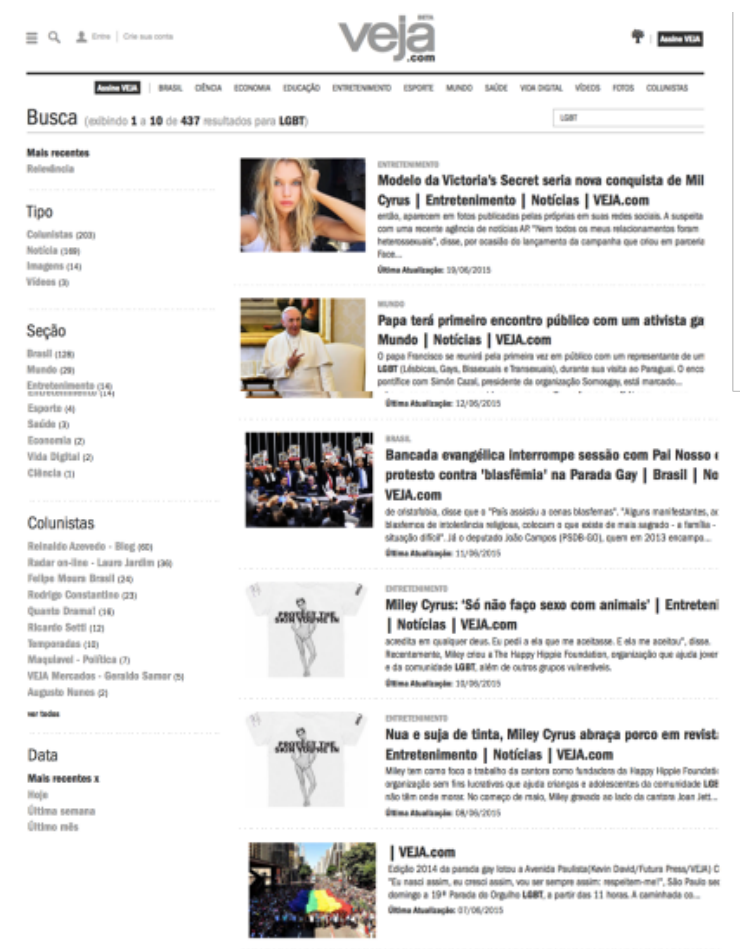

0 cuidado com os conceitos. Ou: Campanha de boicote ao Boticírio 6 intolerat ainda: Foucault vetado em homenagem em universidade nảo 6 censura | Rodri Constantino - VElla.com

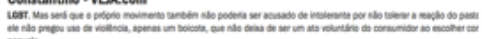
(1)

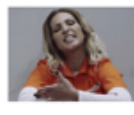

Valesca homenageia seirie 'Orange is the New Black' en música | Entretenimento | Noticias | VELA com

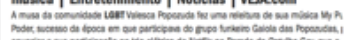

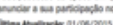

Educaçăo sexual 6 funçà̃o da familla, não das escolas! Oư: Não negguem a biol dessa forma, "progressistas" | Rodrigo Constantino - VELA com

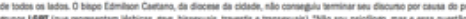

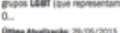

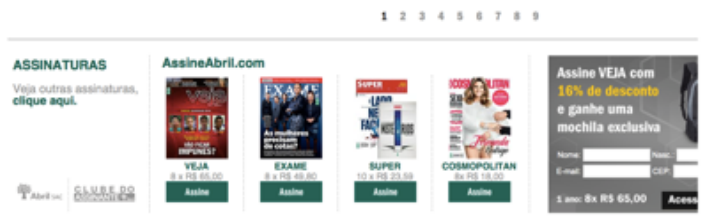


DAS FERRAMENTAS DE BUSCA AO TEXTO:

A CONSTRUÇÃO DA IDENTIDADE LGBT EM REVISTAS DIGITAIS

\title{
Anexo 2 - CartaCapital.com.br
}

\section{CartaCapital hssine}

Voce esta aqui: Pagina Inicial

Buscer

\section{Resultado da buscaLGBT}

210 itens atendem ao seu critério. Filtrar os resultados

Ordenar por relevância - data (mais recente primeiro) · alfabeticamente

\author{
Manifesto pela igualdade de gênero na educação \\ Não discutir gênero nas escolas é ser conivente com a violência \\ sofrida por mulheres, gay, trans... \\ Localizado em Blogs / Territónio de Maira
}

\section{Nove a zero para a democracia}

O STF dá uma goleada em quem desejava impor autorizaçăo prévia para biografias. Por Pedro Alexandre Sanchez

Localizado em Blogs / Farofafa

\section{Conheça os hackers que invadiram o site de \\ Feliciano}

Depois de colorir a home do site oficial do pastor-deputado, o grupo

de adolescentes vai ficar inativo "até sair da mira da polícia"

Localizado em Blogs / Parlatónio

registrado em: Marce Feliciane, Hacken. Protowawe

\section{A crucificação da artista transexual \\ Notas sobre a epidemia de estupidez, a "indignaçāo" seletiva e as \\ estratéglas de difamaçăo \\ Localizado em Sociodade \\ registrado em: Parada LOBI. LCBI, Sâ Paule Jean \\ Whlys. Neymar. Iransexual. Bobicario}

\section{Vão ter de engolir os LGBT}


Matheus Nogueira SCHWARTZMANN, Jean Cristtus PORTELA

A cruzada moralista contra minorias esconde a pilantragem dos que tratam a religiāo como negócio

Localizado em Sociedade

registrado em: LGaI, Mavicio Moraes, Slas Malafaia, Eduardo Cunha, Marse

Eeliciane.Gays Evangélicos

Confira os destaques da edição 853 de CartaCapital Localizado em Revista / Allbum incompleto

\section{Em Brasília, só falta o toque de recolher}

Lei que trata música como ruído fecha bares e casas de show na capital federal

Localizado em Revista / Negócios da China

registrado em: Brasilana. Lei do Siêncie, Brastla

\section{Violência: quem lucra, quem morre}

Um adolescente é assassinado a cada hora: 24 por dia, 42 mil até 2019. Excelente negócio para a indústria armamentista, que elegeu 21 deputados no último pleito Localizado em Blogs / Outras Palavras registrado em: bancada da bala, violencia, policia, chacina, financiamento de empresa. Congresso, brasi

Pedrada, porrada e tiro: Charleston é também aqui Entre o "maluco americano" e o brasileiro que defende a chacina como solução para a violência, a diferença é o acesso ao revólver Localizado em Sociedade

registrado em: desarmemento. Charleston, violkncia

\section{Tod@s junt@s somos fortes (*)}

Săo quase $15 \mathrm{~h}$ do domingo 24 de maio de 2015 e os portōes da Praça das Artes, no centro da cidade de São Paulo, ainda não foram abertos. A Praça das Artes é uma praça pública, administrada pela Localizado em Blogs / Farofafa 
DAS FERRAMENTAS DE BUSCA AO TEXTO: A CONSTRUÇ̃̃̃O DA IDENTIDADE LGBT EM REVISTAS DIGITAIS

\section{CartaCapital}

$\begin{array}{ll}\text { Editera Confiança } & \text { Assinatura } \\ \text { Sobre a Editora } & \text { Assine } \\ \text { CartaCapital } & \text { Central de Adendimento } \\ \text { As Empresas Mais Admiradas no Brasil } & \text { Anuncie } \\ \text { Didlogos Capitais } & \text { Esuipe Comercial } \\ \text { Carta na Escola } & \text { Midia Kit } \\ \text { Carta Fundamental } & \\ \text { Expediente } & \\ \text { Fale com a Redaçlo } & \end{array}$

\section{Simplest}

Artigo recebido em setembro de 2015 e aprovado em dezembro de 2015.

Disponível em: http://seer.fclar.unesp.br/casa 